\title{
LA HISTORIA TROYANA POLIMÉTRICA Y EL POEMA DE ALFONSO XI: ¿DOS OBRAS DE UN MISMO TALLER?
}

\author{
Nuria Larrea Velasco \\ pirois@telecable.es
}

\section{RESUMEN}

La Historia Troyana Polimétrica fue datada por Ramón Menéndez Pidal en 1270, basándose para ello en el empleo de ciertos términos y en una utilización de la dialefa mucho menor que en el Libro de Alexandre. Sin embargo, en los últimos años se ha tendido a retrasar esta fecha de composición. En este artículo se defiende una datación posterior a la de 1270, concretamente en el segundo cuarto del siglo XIV, durante el reinado de Alfonso XI, y se presenta la existencia de una estrecha relación entre la Polimétrica y el Poema de Alfonso XI (1344-48), dadas sus abundantes coincidencias y similitudes, por lo cual se propone la hipótesis de que ambas obras pudieron haber sido compuestas en el mismo taller.

Palabras Clave: Historia Troyana Polimétrica, Poema de Alfonso XI, similitudes, Alfonso XI, taller.

\section{Abstract}

The Polymetrical Troyan History dates back to 1270, according to Ramón Menéndez Pidal, who based this on the use of certains terms and expressions, as well as the use of hiato, lesser than in Alexandre's Book. However, in the past few years the date of the work has been put back. This essay intends to defend the dating of the work to de second quarter of the XIV ${ }^{\text {th }}$ Century, during the reign of King Alfonso XI. Also the essay puts forward the hypothesis that the Polymetrical Troyan History and the Poem of Alfonso XI 
(1344-48) had a close relationship, given their similarities. What's more both could even have been written in the same workshop.

Key words: Polymetrical Troyan History, Poem of Alfonso XI, similarities, King Alfonso XI, workshop.

Nada se nos dice en la Historia Troyana Polimétrica acerca de quién la compuso, por qué, ni cuándo.

Sin embargo, el propio texto muestra el carácter de clerecía del autor: se trata de un poeta y traductor culto. Asimismo, debe tenerse en cuenta que no sólo se ocupa de traducir un original francés (el Roman de Troie, de Benoît de Sainte-Maure) ${ }^{1}$, sino que cuando realiza digresiones propias utiliza otras fuentes (como, por ejemplo, las Etimologías de San Isidoro).

Sobre la fecha de composición, Ramón Menéndez Pidal $^{2}$ es quien ha hecho el análisis más profundo de la obra completa y, de resultas de él, quien ha propuesto una datación que ha sido generalmente aceptada por muchos de quienes con posterioridad han estudiado la Historia Troyana Polimétrica (en adelante, HTP).

Propone Menéndez Pidal la fecha de 1270, cuando se está componiendo la General Estoria y se empieza la Crónica General en el taller alfonsí.

Para decidirse por esta fecha, Menéndez Pidal presenta varias argumentaciones, que son: la utilización de determinados términos, como «sobreseñal», «enatio», «descabeñada», «desmanchar», «albergada»y «trexiello», además del uso de «joya», tomada del francés «joie», por alegría, y la utilización del plural «los dios».

Sin embargo, estos términos que Menéndez Pidal señala como más característicos del siglo XIII, aparecen también en el siglo XIV, incluso bien avanzada la centuria. Como ejemplo, «sobreseñal» y «albergada» aparecen en el Poema de Alfonso XI (1344-48), y «enatio» es utilizado por el Arcipreste de Hita. Así, pues, no son términos exclusivos del siglo XIII, o al menos no todos, como para basar en ellos una datación. Asimismo, si se siguiese este argumento pidaliano, hay un término en la HTP que, en principio, sería propio y característico del siglo XIV, como es la palabra «guitarra», que el autor incluye en una relación de instrumentos. El vocablo pasó del griego al árabe en Oriente y el árabe lo transmitió al romance posiblemente después de cambiar el tipo de instrumento. Lo hallamos en el Arcipreste, que distingue entre la guitarra morisca y la guitarra latina. Asimismo, en el Poema de Alfonso XI encontramos la expresión «guitarra serranista». Es evidente que hay una gran vacilación aún en el uso, prueba de que empezaba a utilizarse para designar el instrumento que hoy conocemos como tal.

Otro de los puntos que Menéndez Pidal destacó para fijar la fecha de composición de la obra es el plural «los dios». A este respecto debe señalarse que en el siglo XIV no es extraña la utilización de este tipo de anómalos plurales, como 'los reys', 'las leys'; por lo tanto, no es base segura para fijar una fecha de redacción.

1 Benoît de Sainte-Maure era un clérigo normando relacionado con la corte de los Plantagenet. Su Roman de Troie (de hacia 1155-1160 y compuesto de 30.316 versos) es la obra fundamental en el desarrollo del tema troyano en la literatura medieval.

2 Se tiliza para este artículo la edición incluida en sus Obras completas. 
Siguiendo con el estudio pidaliano, el gran filólogo incluye la HTP entre las obras del mester de clerecía del siglo XIII, línea en la que ha sido seguido por muchos estudiosos de la literatura, y ello a pesar de que, como es sabido, una de las características fundamentales y quizá la más sobresaliente del mester de clerecía del siglo XIII es la utilización de la cuaderna vía como estrofa métrica, y que, en contraposición, solamente uno de los once poemas de la $H T P^{3}$ está compuesto en ese metro.

Afirma Menéndez Pidal que la obra, en las partes rimadas de la composición, admite más la dialefa que el Libro de Buen Amor, pero presenta una mayor sinalefa que el Libro de Alexandre o las obras de Berceo. De ahí que se decante por una fecha intermedia entre ambos hitos literarios, como puede ser la de 1270. Sin embargo, el poeta de la HTP utiliza tanto la sinalefa como la dialefa, simplemente como recursos, cuando los necesita, con lo cual no pueden servir como elemento de fijación de la época de redacción. Además, convendría detenerse en este capital asunto de la dialefa, y hacer la reflexión de que si el modo de difusión de la Historia Troyana fue la lectura en alta voz para un grupo de personas, como nos indican las abundantísimas expresiones «como avedes oído», «que agora oídes», «de que vos agora fablamos», es bastante complicado imaginarse una recitación con dialefa, ya que la lengua oral impone todo lo contrario. Y habría que añadir, asimismo, que en cuanto a las que, según muchos analistas, se dan en el mester de clerecía, probablemente sean errores de copistas y editores posteriores.

La Historia Troyana Polimétrica está bastante alejada en cuanto a espíritu y forma del mester de clerecía, si bien es verdad que utiliza algunos de sus recursos, lógico si tenemos en cuenta el «éxito» que tales procedimientos tuvieron. Hallamos, asimismo, y de manera muy abundante, la utilización de una serie de fórmulas digamos «mecánicas». Se trata de llamadas al público para señalar un cambio de asunto; llamadas para retomar algo de lo que ya se ha hablado; fórmulas que se usan para indicar la supresión de parte del relato o para decir que, aunque la narración es larga, merece la pena seguir con ella, y fórmulas para encarecer la veracidad del asunto. Todas estas fórmulas son características del mester de clerecía, pero no hay que olvidar que también de todo cronista medieval. Las hallamos frecuentemente en la HTP, lo que revela que el autor es un hombre culto que conoce perfectamente la tradición literaria y que utiliza elementos y fórmulas típicas que han tenido éxito y gozan del favor del público para la confección de su obra. Sin embargo, ese uso no tiene por qué llevar implícito que la HTP deba pertenecer al mester, al menos al mester del siglo XIII, pues no ha de olvidarse que se ha establecido la existencia de dos mesteres de clerecía, uno propio del siglo XIII y otro del siglo XIV, en el que quizá pudiese tener su filiación la HTP. Sin embargo, es preciso hacer referencia al análisis de Isabel Uría:

No es arbitraria la exclusión de los poemas del siglo xIV que tradicionalmente se venían considerando del mester de clerecía. Esos poemas no se ajustan a los rasgos formales proclamados como genuinos y característicos de esta escuela. Además, también se separan en aspectos de carácter histórico-social y cultural.

3 Once son los poemas que han llegado hasta nosotros, intercalados entre la prosa. Teniendo en cuenta que se ha perdido parte de la obra, por el principio y por el final, es de suponer que se han perdido también poemas. Además, se advierte en el manuscrito una tendencia a prosificar las partes rimadas, como lo demuestra el hecho de que en la prosa se hallan con facilidad verdaderos versos. 
Efectivamente, es entre esos poemas del siglo XIV que presentan unos rasgos lingüísticos, formales y temáticos distintos respecto a los poemas del siglo XIII donde mejor parece «encajar» la $H T P$.

Por otra parte, se ha querido también ver en la obra cierta relación con el taller historiográfico alfonsí, teniendo en cuenta que la HTP es, en principio, una traducción y que Menéndez Pidal la data hacia 1270, cuando se están haciendo los grandes trabajos historiográficos en el taller alfonsí. Sin embargo, la HTP se halla bastante alejada de las obras alfonsíes. En primer lugar, nada de su traducción ha sido empleado para la confección de estas obras historiográficas, ni la manera de trabajar del taller alfonsí tiene nada que ver con la HTP y su «modus operandi». La General Estoria (planteada como una ambiciosa historia universal desde la Creación hasta el reinado de Alfonso X) parece un repertorio de traducciones en el que sus compiladores trabajaron con ahínco con el fin de enlazar las diversas fuentes en el hilo de una narración que tuviera sentido e ilustrada con muchas citas de los textos originales o tomadas de compilaciones enciclopédicas medievales. Alfonso y sus colaboradores no sólo traducen, sino que glosan sus préstamos, haciendo comentarios sobre el contenido, el vocabulario y las implicaciones del material. El interés por la cultura clásica y profana, que se combina con un propósito moral cristiano, está de acuerdo con el concepto de la educación que tenía Alfonso X, un eco de lo cual hallamos en la HTP, por ejemplo en algunas sentencias y refranes, pero sólo eso. El modo del taller historiográfico alfonsí tiene algunos elementos característicos y definitorios: los materiales proceden de cuantas fuentes están a su alcance. El hábito medieval de leer los grandes textos de la época con escolios es clave del modo alfonsí de «traducir» o utilizar las fuentes. Por este motivo, los compiladores recurren al sistema de la «explanatio», de «no servirse del texto sino con la glosa». Y nos ilustran abundantemente sobre cuantas personas, costumbres, cosas, animales, lugares aparecen; las acciones se desmenuzan, y se multiplican las explicaciones psicológicas. Pero nada de esto hay en la HTP. Precisamente, la forma y el sentido de la obra y, sobre todo, la mezcla de prosa y poesía, irían contra la manera de trabajar «histórica» del taller alfonsí, así como los episodios amorosos tampoco se ajustarían en las «normas» de estas obras alfonsíes.

\section{Hacia una datación de la Historia Troyana Polimétrica}

Como se ha señalado, los argumentos de Menéndez Pidal no otorgan una fiabilidad rigurosa a la hora de determinar la fecha de composición de la HTP. Y puesto que ninguna mención sobre época o autor nos suministra la propia obra, ni ninguna alusión directa o indirecta se halla en ella, o en otras, se habrá de echar mano de otros elementos, como el contexto histórico, social y literario en el que la obra pudo ser escrita.

En cuanto a este contexto histórico-social, en la primera mitad del siglo XIV, período que coincide, mayormente, con el reinado de Alfonso XI, conviene recordar que se produjo una importante crisis socioeconómica, agravada por los conflictos políticos que se sucedieron en Castilla durante la minoría de edad del monarca y los primeros años de su reinado. Sin embargo, aun en esta crítica situación, se dio, paradójicamente, un importante auge cultural que ya había comenzado a desarrollarse en los últimos años del siglo anterior. 
En ese tiempo, las ciudades proliferaron y crecieron y, paralelalmente, el reino experimentó un fuerte desarrollo comercial, lo cual trajo consigo que la burguesía comenzase a protagonizar un papel cada vez más relevante, cuya consecuencia fue la renovación de las ideas y las costumbres. Asimismo, se fundan universidades, que trajeron consigo un espíritu de cambio, menos teocéntrico y más pragmático. Como señala Alan Deyermond, acerca del siglo XIV:

Hubo un creciente ritmo del desarrollo intelectual: la fundación de nuevas universidades y escuelas [...]. Si añadimos al balance positivo los avances desde el punto de vista tecnológico, las turbaciones políticas, sociales y económicas están en su conjunto compensadas, y la situación, en términos generales, ofrece a la literatura la oportunidad de desarrollarse.

Por otro lado, Alfonso XI luchó denodadamente contra la alta nobleza, especialmente contra algunos de sus más elevados representantes, que le habían, literalmente, desafiado. El reinado de Alfonso XI se corresponde con lo que algunos historiadores llaman la «agonía de la vieja nobleza». El rey dio un fuerte impulso a la caballería, con la reanudación de la Reconquista y con las nuevas perspectivas de hacer «carrera» que se abrían al común y, por otro lado, permitió que los hidalgos y los caballeros se introdujeran en la jerarquía nobiliaria. Dio rienda suelta, en fin, a un nuevo modelo caballeresco, buscando un renovado apoyo social para su poder. Puede hablarse, pues, de un contexto con otros valores y otras intenciones, de un «buen caldo de cultivo» en el que HTP pudo perfectamente componerse y en el que podría ser encuadrada.

La HTP es una obra en prosa en la que se intercalan algunos poemas: sólo once han llegado hasta nuestros días. Seis de ellos están en cuarteta octosílaba, metro utilizado, por ejemplo, en el Poema de Alfonso XI. Otro poema, en cuarteta heptasílaba, como los Proverbios morales, de Sem Tob. Y uno, en cuaderna vía, metro que también utiliza el Arcipreste de Hita. Todas, obras de hacia mediados del siglo XIV. Las otras tres combinaciones estróficas empleadas en la HTP, la sextina octosílaba, la décima y el pareado, reconoce Menéndez Pidal que son raras en nuestra literatura y considera que se trata de un rasgo original del anónimo poeta.

Estas coincidencias de uso en las combinaciones estróficas entre la HTP y otras obras compuestas en el siglo XIV llevan a pensar en una datación en esta misma centuria, como ya lo hiciera Antonio Solalinde en un principio, y a retrasar, por tanto, la fecha defendida por Menéndez Pidal.

Retrasar la fecha en que se compuso la HTP es lo que ha hecho Juan Casas Rigall al señalar que podría ser coetánea o incluso posterior a la Crónica Troyana ${ }^{4}$, acabada de copiar e iluminar en 1350 para la cámara regia. En su opinión, una y otra no son traducciones independientes de una versión del Roman de Troie, sino textos estrechamente ligados. Ambas obras serían adaptaciones hispanas que derivarían de una misma fuente iberorrománica, escrita en gallego o en portugués ${ }^{5}$. Pero este texto del que habla Casas Rigall no ha llegado a nuestros días, ni tampoco se tiene ninguna referencia o indicio acerca de él. Es decir, no hay ninguna prueba de que haya existido, aunque las dos obras

\footnotetext{
4 También denominada Versión de Alfonso XI, pues fue un encargo hecho por el rey.

5 Y puesto que la Historia Troyana Polimétrica derivaría de esa fuente gallega o portuguesa, destaca Casas Rigall que los leonesismos que presenta la HTP no serían tales, sino galleguismos.
} 
sí que parecen estar muy ligadas, tal vez únicamente porque las dos traducen el mismo texto o quizá porque una tuvo delante a la otra.

Y en fin, para postular una datación en el XIV de la HTP, es importante tener presente la observación de Francisco Rico al incidir en un rasgo peculiar de la literatura del siglo XIV, que es la proliferación de obras misceláneas: lo que predomina en ellas es la variedad y la mezcla de temas, materias y formas. Por lo tanto, el gusto por el hibridismo sería dominante en esta época. Según Rico,

[...] Durante decenios, las letras europeas registran una desazón, un desconcierto que se refleja en una insegura voluntad de experimentación e innumerables tanteos. El máximo exponente de la crisis son las obras mestizas, los textos cruzados, que combinando formas, asuntos y modos que hasta la fecha no se habían cruzado entre sí, intentan y en ocasiones consiguen prolongar la vida útil de los viejos mimbres $[\ldots]{ }^{6}$

\section{la Historia Troyana Polimétrica y el Poema de Alfonso XI: ¿sólo coincidencias CASUALES? ¿UNA MERA INFLUENCIA?}

Una vez retrasada la fecha de redacción hasta el siglo XIV, en este punto es preciso destacar las coincidencias que se pueden observar entre la HTP y el Poema de Alfonso $X I$, de hacia 1344-48 (en adelante $P A O)^{7}$. Se trata de similitudes que difícilmente pueden ser consideradas casuales, o una mera influencia.

El PAO es un texto de corte donde se narran diferentes episodios del reinado de Alfonso XI, fundamentalmente de su empeño reconquistador. Como señala Juan Victorio, es un canto de cruzada en el que se elogia a todo un colectivo para captar su ánimo y canalizarlo para un fin: seguir esa labor reconquistadora, que en ese preciso momento apuntaba al cerco y toma de Gibraltar. También tiene pasajes de un intenso lirismo, que son, por otro lado, los más logrados.

La HTP canta, asimismo, unas gestas bélicas en una prosa que sigue muy libremente a su fuente francesa. Los pasajes más intensos son aquellos que están en verso y que nos describen los sentimientos de algunos de los protagonistas, como, por ejemplo, los de Troilo y Briseida.

La estrofa escogida por el autor del $P A O$ y que aparece en más de la mitad de los poemas de la HTP es la cuarteta octosílaba. Menéndez Pidal indica que es una estrofa «muy empleada por la lírica gallego-portuguesa en el siglo XIII, y luego en el XIV en la poesía lírica de Alfonso XI», para añadir que «es hermana de la cuarteta eneasílaba, menos usada, y de la heptasílaba».

Es ésta una estrofa narrativamente nueva, por lo que resulta un tanto extraño que el autor del $P A O$ la adoptase, en lugar, por ejemplo, de la cuaderna vía, con una larga y asentada tradición. El autor de la HTP la utiliza en seis de los poemas, el III, VI, VII, VIII, IX y X, utilizando la variante heptasílaba en el poema V. Quedan, pues, cuatro poemas en un metro diferente, los cuatro distintos: sextina octosílaba (poema I), décima de

6 Cabe preguntarse al respecto: ¿No responde la HTP totalmente a esa característica de hibridismo con su mezcla de prosa y verso, su gran variedad métrica y su inclusión de episodios amorosos entre el relato bélico?

7 Se ha utilizado para este artículo la edición de Juan Victorio. 
cuatro y ocho sílabas (poema II), cuaderna vía (poema IV) y pareado octosílabo (poema $\mathrm{XI}$ ). Ya en la primera mitad del siglo XIV se había producido una importante decadencia de la cuaderna vía, un agotamiento de esta forma de expresión que tan buenos resultados había dado en el siglo XIII, por lo que había que buscar una nueva forma narrativa, una nueva forma de expresividad literaria que se adecuase, además, a los «nuevos tiempos». ¿Podrían ser los distintos tipos de estrofas de la HTP un «ensayo» para encontrar esa nueva forma? Había que probar el nuevo metro y la materia troyana podía resultar el campo de pruebas adecuado.

En cuanto a la lengua, no deben olvidarse tampoco los leonesismos que, no en número excesivo, recorren la HTP. ¿Y no se ha debatido ampliamente sobre los dialectalismos del $P A O$, sus rasgos occidentales? ${ }^{8}$

Las semejanzas entre las dos obras no deberían ser tenidas por casuales o anecdóticas. En primer lugar, no pocos de los versos de las dos obras contienen una misma expresión, un mismo sentimiento, una misma inspiración.

Se lee en el PAO, estrofas 1865 y 1866 :

Mesquino, ¿por qué só vivo?

¡Ay, rey triste, sin ventura!

¡ay, rey vil, ay, rey captivo!

¡ay, rey lleno de amargura!

¡ay, qué ventura tan fuerte!

¡qué quebranto y qué caída!

¡ay, Dios, pidote la muerte!

¡mejor me es que la vida!

Y en la $H T P$, poema I:

Mas, ay mesquino, ¿qué digo?

ay, Dios, ¿cómo no me muero?

$[\ldots .$.

Por mi mal es la mi vida

pora mi mal fue venida,

Señor, aquesta batalla,

qué será de mí, ¡mesquino!

O también, en el poema XI, y con el mismo tipo de aliteración:

Ay mi fijo, ay mi señor

ay mi bien, ay mi amor

ay mi lunbre, ay mi amigo [...]

Mismos recursos, pero, sobre todo, mismo aliento poético.

Pero las coincidencias, de todos modos, no acaban aquí. No son semejanzas, se podría decir, totalmente plenas, en cuanto a las circunstancias, sino identificaciones parciales sobre algún aspecto concreto, entre los diversos personajes o hechos.

8 Diego Catalán fue quien más estudió la cuestión de los rasgos dialectales (en principio, leoneses) del Poema de Alfonso XI. Sin embargo, no llegó a identificar plenamente esa lengua, afirmando únicamente que se trataba de una lengua occidental. 
Héctor, el príncipe troyano, el paladín del ejército de Ilión, tiene su correspondencia con el rey Alfonso. Héctor es el personaje principal del texto troyano. Aparece en la mayoría de los capítulos; más que Aquiles, que el propio Agamenón, jefe de los ejércitos griegos, Paris o cualquier otro de los guerreros ya sean de un bando o de otro, y el único que recibe el tratamiento de don, prácticamente en todo el texto. La identificación entre el rey Alfonso y Héctor es muy clara en diversos pasajes y, desde luego, no pasaría desapercibida para un receptor atento. Los versos del $P A O$ «el su cuerpo muy lozano / guarnido a muy gran brío» o «e dio un bramido fuerte / como un bravo león» o «yaziase rebolviendo / como un bravo león» tienen su correspondencia con la prosa de la HTP «e desque sobio en su cavallo, con la gran saña que avíe, fizo tan gran mortandad en los griegos, que sería muy grave cosa de contar, ca tan bravo andava como un león» o «e iva don Héctor tan loçano e tan bravo como un león».

Se trata de los mismos epítetos utilizados en ambos textos para describir a Alfonso XI y a Héctor. Los dos son los más valientes, los mejores guerreros, ambos «bravo como león», de «cuerpo muy lozano» y luchan «con gran brío» y «con gran saña».

Tanto Alfonso como Héctor no son sólo la cabeza de su ejército, sino también de su reino. Se lee en el PAO (estrofas 933 y 934):

[...] E don Alfonso d'España

éste prended(lo) a vida

que es rey muy atrevido

a que todos miedo han:

si éste fuer conquerido

los cristianos lo serán

Es la misma idea que aparece en la HTP: «ca él es todo el esfuerço e todo el bien de los troyanos», abundando en la idea de que si ellos son derrotados, si ellos desfallecen o mueren, sus reinos desaparecerán o se perderán.

La identificación de ambos personajes es total en dos pasajes en los que se habla de sus cualidades como guerreros y defensores de sus reinos.

En la HTP, en el poema III, compuesto precisamente en cuartetas octosílabas, se dice:

Este es su esfuerzo e su bien

Este es su castiello fuerte

[... ]

este su señor e rey

es, en cuyo poder son,

este es su dios e su ley

este les guia e otro non

este es su recobramiento

su escudo e su manto

este es el su ardimiento 
Y en el $P A O$, en la escena donde el Santo Padre pide oraciones por Alfonso, paladín y protector de la Cristiandad, por su cruzada contra los invasores musulmanes (estrofas 1918, 1921 y 1922):

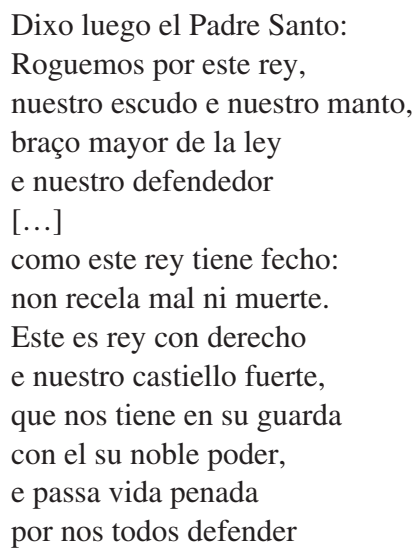

Llama la atención que, aparte de que se trata del mismo espíritu en ambas escenas, con el mismo esquema compositivo, hay incluso versos idénticos, que no dejan lugar a dudas sobre el objetivo de los mismos, que es identificar a Alfonso XI con Héctor, paladín y gran guerrero, mayoral de los ejércitos troyanos y héroe de la Antigüedad clásica. Ambos personajes son «nuestro escudo e nuestro manto» y «nuestro castiello fuerte». De esta manera los dos quedan unidos. Esta identificación supone para Alfonso quedar ligado a un héroe clásico, con todo lo que conlleva de prestigio y afianzamiento institucional y personal: Alfonso, elevado a la categoría de héroe clásico.

Reseñar, aunque se trate de un mínimo detalle, que sólo de Alfonso y Héctor se da el nombre de sus respectivos caballos: Valencia en el primer caso y Galatea en el segundo. De ningún otro guerrero de ambas obras se señala el nombre de su montura.

Asimimsmo, no cabe ignorar un conjunto de circunstancias que, aunque no idénticas, sí parecen estár relacionadas muy cercanamente. En el caso de la narración troyana, Elena, esposa del rey griego Menelao, es raptada por Paris, del que se enamora, y llevada a Troya, donde la pareja es considerada como tal. Se señala en la HTP, por boca de Héctor:

[...] E don Héctor dixol estonçe juegando: por dios, fermosa Elena, si vos oy en la batalla vierades la muy gran pena en que andavan sin falla anbos los vuestros maridos uno a otro buscando por los canpos e por exidos muy bravamiente lidiando, e de cómo fue llagado el uno mal en la pierna, e el otro derrivado en la yerva verde e tierna, si los quesiesedes bien, mal vos sería en verlos $[\ldots]$

Con toda naturalidad se nos habla de los «dos maridos» de Elena; es más, en el pasaje siguiente vemos que Elena no está angustiada por sus «dos maridos», sino sólo por Héctor, que está herido.

La identificación no se establece con doña Leonor, favorita del rey, que, en todo caso, era ya viuda cuando Alfonso y ella se enamoran y entablan relaciones. La identificación se hace con Alfonso, cuyo reinado se caracterizó por tener dos reinas: la legítima, 
la de derecho, María, y la amada y reina de hecho, Leonor. Esta relación adúltera trajo no pocos quebraderos de cabeza al rey, por cuanto María era la hija del rey de Portugal. Para Alfonso era vital el buen entendimiento con el monarca lusitano, no sólo para evitar tensiones y guerras entre ambos reinos, sino porque el rey portugués podía ser un colaborador sumamente importante en la Reconquista.

Si en la antigua Grecia se veía con naturalidad que una mujer tuviese dos maridos, ¿por qué Alfonso no iba a poder tener dos mujeres?

Elena y Leonor se identifican en sus anómalas circunstancias vitales y sobre todo por sus características físicas. De Elena se dice en la HTP que

E parose y Elena la muy fermosa, con muy gran miedo que avía e asi estava guarnida de muchas piedras preciosas que resplandecían en derredor todo el logar do ella estava; e parecía la su cara tan fresca como una rosa

En el poema alfonsino, doña Leonor es descrita, asimismo, de manera sumamente positiva (estrofas $371,372,373$ y 374 ):

E Dios por su piadad,

le dio muy noble fegura,

e conplióla de bondad

e de muy gran fermosura.

E diole seso e sabencia

e de razón la conplió,

de gracia e de parencia,

flor de quantas omne vio;

señora de gran nobleça

contra Dios muy omildosa,

quita de mal e vileça

apurada como rosa

Aquesta muy noble flor

siempre nonbrada será

e su bondad e valor

por espejo fincará

Las dos mujeres son descritas hermosas como «rosas» y siempre con epítetos muy ponderativos, nada negativo se nos dice de ellas. Es éste un aspecto que no parece responder a una ideología programática fiel a la tradición de alabanza y descripción positiva de las mujeres del entorno real, pues en la HTP se halla una durísima digresión contra el carácter femenino y en el $P A O$ respecto a la reina María, entre las virtudes y cualidades (cuantitativamente menores con respecto a las de Leonor) que se le otorgan, se incluye «que nasció en Portogal».

Ciertamente, las críticas y los expeditivos consejos a Alfonso contra su adúltero amor le trajeron al monarca y a su dama muchos conflictos tanto de tipo personal como políticos.

En la narración troyana se da cuenta, asimismo, de las habladurías: «E tan grande era y la mortandad que dezían y tales avie que por mal naciera Elena e por mal la feziera Dios, ca por ella se avía de perder todo el mundo». 
También en la profecía de Casandra se echa la culpa de la guerra a Elena, pero sin incidir en los motivos concretos (poema II):

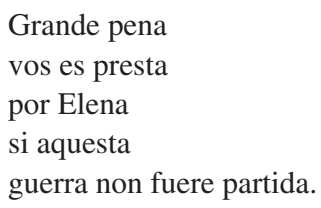

Pero todas estas palabras y las desgraciadas consecuencias que Casandra sacude sobre sus compatriotas troyanos sólo servirán para que la encierren (II):

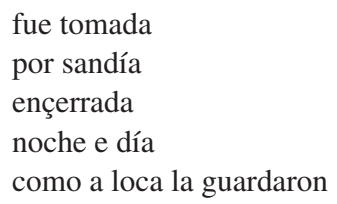

Sin embargo, en términos del propio rey de Troya, Príamo, no se señala a Elena como culpable de la situación, sino a los griegos, sin concretar causa ninguna, salvo quizás la de conquistar un ambicionado territorio:

Començó el rey Príamo a fablar e dixo: Amigos, bien sabedes que tenedes preso al rey Thoas $[\ldots]$ e vieno nos acá deseredar e echar de nuestro regno e de nuestra tierra e confondernos si él podiese.

Palabras que son repetidas del mismo modo en otros momentos y por otros personajes troyanos.

No acaban en éstas las semejanzas entre la $H T P$ y el PAO. En ambas obras aparecen, en diferentes ocasiones, tanto los hijos que Alfonso tuvo con Leonor como los hijos que Príamo «oviera en dueñas e en donzellas e en muy fijas de algo», es decir, bastardos en ambos casos. Y las descripciones son positivas en los dos relatos.

PAO (estrofa 1479):
Amigos, por vos non finque
de guardar bien el pendón
del mi fijo don Enrique,
que amo de coraçón.
Otro pendón llevaredes
de don Tello fijo amado:
a Tarifa llegaredes,
este es el mi mandado

HTP: (p. 247)

[...] Si non fuera por diez hermanos de don Hector que estavan con la otra hueste de los troyanos en el logar do los don Hector dexara [...]. Derrancharon todos diez contra aquellas azes tan de rezio como unos leones.

E se mostraron todos por muy buenos cavalleros e ayudaron bien a su hermano [...]. E desta guisa fezieron estos diez hermanos muy gran daño en los griegos, luego que allegaro e acorrieron a su hermano don Hector muy esforçadamiente. 
Casualmente, como los hijos de Alfonso y Leonor, son diez los hermanos de Héctor (así nombrados, y no hermanastros), que también participan en la batalla de una manera importante, ayudando en diferentes acciones guerreras al príncipe troyano, con gran valentía y arrojo.

Otro aspecto no menos relevante es el gusto o la inclinación que en ambos textos se aprecia por incluir dichos, sentencias o refranes, que no tienen ningún fin moralizador, sino más bien práctico, o como resultado de la experiencia adquirida.

HTP: «De los escarmentados se fazen los arteros», «el mal de muchos conorte es», «todo amor es vençido por el nuevo entendedor» o «mudase el amor con el nuevo», «quien fallar a moger fuerte dé loor a Dios por ende», «mogier casta e fermosa más debe ser preçiada que piedra preçiosa», «ama a quien non te ama, responde a quien non te llama, andarás carrera vana», «e suele aquesto muchas vezes conteçer: que resçibe omne bien donde non lo atiende; e por esto dize la palabra: faz bien e non cates a quien», «ca loco es el que non ha miedo de ninguna cosa», «onde non cuida omne quel verná mal, de alli le viene».

Y en el PAO: «El omne de seso poco / por su lengua toma muerte», «non tienen omne por loco / si puede foir de muerte», «ave que non tiene alas / nunca bien puede bolar», «omne que non ha amor / nunca puede bien fazer», «del mal tomad lo más poco».

Nunca se deja escapar en ninguno de los dos relatos la ocasión para introducir en digresiones propias o interrupciones de la acción más puramente bélica esta especie de refranes que más bien son advertencias o constataciones de lo que pasa en determinadas situaciones de la vida, pero sin ningún afán moralizante.

Por último, otra coincidencia con visos de poco accidental. En la HTP, en la escena donde se describe una cámara maravillosa, se incluye una lista de instrumentos musicales. Esta relación aparece en el Roman de Troie y es un motivo frecuente en la literatura medieval francesa. La enumeración en el relato troyano es la siguiente:

Que non ha estromento en el mundo, nin guitarra, quier harpa, quier sinfonía, quier rota o viuela o armonía o salterio o çitola o vuerganos o cualquier otro estromento que ella non tañiese.

Prácticamente, son los mismos instrumentos que aparecen en la obra francesa, a excepción de la guitarra. Se puede decir que el autor de la HTP traduce aquí literalmente a su fuente francesa.

El PAO ofrece una relación muy parecida (408, 409 y 4109):

El laúd ivan tañendo, estromento falaguero la vivuela entremetiendo el rabé con el salterio, la guitarra serranisca, estromento con razón la exabebe morisca allá en medio canón, la gaita, que es sotil, con que todos plazer han otro estromentos mil: la farpa de don Tristán 
En este caso, además de la inclusión de la guitarra que se ha visto anteriormente, se incluye la gaita. Podría pensarse, en este caso, que un texto simplemente fue la fuente del otro, pero el conjunto de todas las coincidencias analizadas es bastante significativo y parece responder a un objetivo muy definido como para considerarlo una mera influencia literaria.

Para concluir este análisis de paralelismos, cabe añadir dos puntos que, aunque menores, pueden revelar hasta qué punto llega la relación entre ambos textos. Se trata de las profecías que se hallan en las dos obras y del gusto que el autor tiene por la heráldica en ambas.

En cuanto al primer aspecto, se cuentan las profecías de Casandra, en el relato troyano, y las de Fátima, en el poema alfonsino. En ambos casos sus consejos y advertencias no serán tenidos en cuenta e incluso en el caso de Casandra será tachada de loca y encerrada.

$H T P$ (p. 275):

E Casandra, la fija del rey Príamo, que vio aqueste daño tan grande e aquestos duelos tan sin guisa, començó de profetizar por spíritu santo del destroimiento de Troya e a castigar los troyanos e a dezirles que se partiesen de aquella guerra, maltrayéndolos muy fuerte...

Por otra parte, Fátima, esposa de Albohacén, rey de los benimerines, le desaconseja que invada el Estrecho después de haber consultado con las estrellas (965 y ss.):
Siendo niña e donzella
Sopiestes siempre la arte
De la fermosa estrella
Que los fechos bien departe.
Reína, una fazaña
de vos quiero yo saber:
si conqueriré a España
e tornarla a mi poder

En ambos casos, las dos mujeres auguran «gran desonra» para sus pueblos si no son creídas o no se les hace caso, como así sucederá al final.

Sin embargo, hay una diferencia entre las dos predicciones: Casandra profetiza por el «spíritu santo», todo un anacronismo que sólo pretende acercar el relato a su receptor, mientras que Fátima, musulmana y en el lado enemigo, interpreta las estrellas, gracias a su conocimiento de ese arte.

La otra semejanza citada tiene que ver con el interés que se muestra en ambos relatos por la heráldica. Las dos obras suelen hacer con frecuencia referencia a cuestiones de este tipo.

En la HTP se pueden hallar muchas de estas referencias, como «e trayan todas las armas cobiertas de oro e de piedras preçiosas, e las borlas de oro fres, e las sobreseñales e los pendones de purpola» (p. 228) o «e éste traya el su pendón muy devisado por ser más conosçido entre todos los otros» (p. 287), «...en el escudo que traya, a flores el canpo de oro e las flores de azul» (p. 318).

Y en el PAO (1555), «llevaba sobreseñales / el su pendón bien tendido / entre los sus naturales» refiriéndose en este caso al rey Alfonso, pero son muchas, asimismo, las alusiones a los pendones y demás emblemas de los distintos caballeros que luchan con 
Alfonso: «rastros de sangre fazía / por do iva el su pendón» (1741), «fijos dalgo muchos son / con el pendón de cruzada» (1724), «con el pendón de Santiago / van delante los cristianos» (2414).

Son referencias que no añaden nada a la narración, pero que, especialmente en el caso del $P A O$, pueden tener otro cometido.

Es necesario recordar que el reinado de Alfonso XI se caracteriza por dos circunstancias fundamentales: el sometimiento de la alta nobleza, que dio no pocos quebraderos de cabeza a Alfonso, y cuyas tropelías venían sucediéndose ya desde los tiempos de su minoridad, y el emprendimiento de la actividad reconquistadora. Alfonso apoyó (y se apoyó) fundamentalmente a la baja nobleza para así contrarrestar el poder de la alta aristocracia, tan reacia a su poder. Se creó, pues, un nuevo modelo caballeresco. A lo más alto se podía acceder por méritos, por los servicios prestados, y no sólo por pertenecer a la más rancia nobleza del reino. A este respecto, el mismo monarca fue el creador de una nueva orden caballeresca, la Orden de la Banda, que permitía extender a otros grupos sociales el honor que la caballería otorgaba. De ahí ese interés en destacar los pendones y estandartes no sólo de los caballeros pertenecientes a la nobleza de más rancio abolengo, sino a otro tipo de hombres que no provenían de altos linajes pero que, con Alfonso, sí que podían esperar su subida en el escalafón, y había que mostrar constancia de ello. A toda esta situación política hay que añadir las empresas reconquistadoras que quería llevar a cabo Alfonso, para lo cual tenía que aglutinar e incentivar los distintos intereses de todos sus súbditos.

En fin, la HTP trata de una guerra de la Antigüedad, guerra famosa, en la que los contendientes de ambos bandos son elogiados por su esfuerzo y honor en la batalla. Los contemporáneos del autor de la HTP podrían verse reflejados en esos héroes que quieren demostrar o buscan «gran prez de caballería». Para ello, los anacronismos: había que acercar la guerra troyana a sus coetáneos a fin de que la «sintiesen» mejor, la «viviesen» más cercanamente; por eso, esta famosa guerra de la Antigüedad parece una guerra medieval, con las armas, las estrategias, los modos, etcétera, característicos del Medievo.

Sin embargo, el relato troyano consta de muchos más elementos. La cuestión amorosa cobra en ella una importancia desconocida, y es porque gusta al público, en el que, aparte de un mayor refinamiento de la sociedad y otros gustos, las mujeres tienen un mayor peso. Este nuevo gusto está infiltrado totalmente por el amor cortés. Ya no sólo se trata de épica para consumo de la aristocracia. El público de este tipo de obras se ha extendido y vuelto mucho más variado. Sin olvidar que el rey Alfonso gustaba de la lírica y él mismo escribió poemas de amor.

Tenemos, pues, que por temática y recursos métricos, gusto del público, contexto literario, la HTP debería ser considerada hija del siglo XIv, pues es en el entorno cortesano de Alfonso donde mejor encaja la obra, ${ }^{9}$ en el caldo de cultivo que suponen otras obras compuestas en el segundo cuarto del siglo XIV.

$\mathrm{Y}$ asimismo, se ha señalado toda una serie de coincidencias en la $H T P$ y el $P A O$ que no pueden ser tomadas como puramente casuales, ya que son de todo tipo: mismo tipo

\footnotetext{
${ }^{9}$ En opinión de Francisco Bautista, «las dos obras aquí mencionadas (la HTP y el $P A O$ ) permiten entrever el desarrollo de una literatura en romance castellano que da un contexto y una materia para la parodia de Juan Ruiz». Aboga por una datación más tardía para la $H T P$, «justamente en el contexto de la literatura en la corte de Alfonso XI».
} 
de estrofa, evidentes paralelismos entre algunos personajes y escenas, idéntico aliento en no pocos pasajes poéticos... Por todo ello, no sería descabellado afirmar que ambas obras pueden haberse gestado y compuesto en el mismo taller, en el seno de la corte de Alfonso XI, y así se explicarían las conexiones que, sin duda, existen entre ambos textos.

\section{OBRAS CITADAS}

Blecua, Alberto (2001): Libro de Buen Amor, Madrid, Cátedra.

BAUtista, Francisco (2007): contribución «Recepción y cortesía en el Libro de Buen Amor», en II Congreso Internacional «Juan Ruiz, Arcipreste de Hita, el Libro de Buen Amor».

Baumgartner, Emmanuèle y Vielliard, Françoise (1998): Roman de Troie, París, Lettres Gothiques.

Casas Rigall, Juan (1999): La materia de Troya en las letras romances del siglo XII hispano, Universidad de Santiago de Compostela.

Catalán Menéndez-Pidal, Diego (1976): Gran Crónica de Alfonso XI, Madrid, Crítica

Deyermond, Alan (1980): tomo Edad Media, de Historia y Crítica de la Literatura Española, Barcelona, Crítica, p. 185-186.

García Solalinde, Antonio (1916): «Las versiones españolas del Roman de Troie», RFE, III.

Menéndez Pidal, Ramón (1976): Historia Troyana Polimétrica, Obras Completas, tomo XII, Madrid, Espasa-Calpe, p. 183-403.

Rico, Francisco (1984): Alfonso el Sabio y la General Estoria, Barcelona, Ariel, p. 168-188.

Uría Maqua, Isabel (2000): Panorama crítico del mester de clerecía, Madrid, Castalia, p. 153-162. Victorio, Juan (1991): Poema de Alfonso XI, Madrid, Cátedra. 